\title{
A EDUCAÇÃO AMBIENTAL BRASILEIRA: HISTÓRIA E ADJETIVAÇÕES
}

Camila Aparecida da Cruz ${ }^{1}$

Ismail Barra Nova de Melo²

Silvio César Moral Marques ${ }^{3}$

\section{Resumo}

Um retorno à história recente do país permitirá um entendimento de como os movimentos sociais foram relevantes para a construção das diversas concepções que formam a complexa teia da Educação Ambiental. Em contrapartida, será ponderado o reflexo que a ditadura militar também produziu no seu desenvolvimento. Assim, após a apresentação do contexto histórico, ao revisitar as produções científicas pertinentes ao assunto e o seu referencial teórico-conceitual, esse artigo pretende compreender os fundamentos, as orientações e as perspectivas da Educação Ambiental adjetivada como crítica e aquela dita conservadora.

Palavras-chave: Educação Ambiental; Contexto Histórico; Adjetivações.

${ }^{1}$ Universidade Federal de São Carlos, campus Sorocaba. E-mail: camilaac.ferreira@hotmail.com 2Universidade Federal de São Carlos, campus Sorocaba. E-mail: ismail@ufscar.br

3Universidade Federal de São Carlos, campus Sorocaba. E-mail: silviocmm@ufscar.br

Revbea, São Paulo, V. 11, No 1: 183-195, 2016.

revista brasileira educação ambiental 


\section{Introdução}

A emergência das questões ambientais tornou-se parte da temática mundial quando foi possível perceber que o estilo de vida predatório adotado por diversas sociedades ao redor do mundo ampliava os impactos negativos sobre o meio ambiente e contribuíam para a diminuição da qualidade de vida da população. Assim, pode-se afirmar que "[...] o meio ambiente se tornou problemático, porque se intensificaram os impactos e o mal-estar, individuais e sociais, provenientes da relação entre sociedade e meio ambiente" (LIMA, 2011, p.27).

Nesse sentido Leff (2001) assegura que os problemas ambientais são resultados de uma grande crise civilizatória em que o ser humano se colocou como ser a parte da natureza, e esta apenas como uma mera fornecedora de recursos, assim, o ponto de partida ao se discutir as questões ambientais deve ser, obrigatoriamente, a revisão do posicionamento humano no mundo. Portanto, para se avançar nesse diálogo é imprescindível o entendimento de que o ser humano é parte integrante e indissociável do meio ambiente.

Em sua obra, Carvalho (1998) vai ao encontro do pensamento defendido por Leff ao afirmar que:

Uma das coisas que o olhar ecológico ajudou a evidenciar foi a estreita conexão entre os processos naturais de degradação ambiental e os modos sociais de uso dos recursos naturais. $\mathrm{O}$ que passou a constituir-se como problemática socioambiental decorre de uma noção de meio ambiente que colocou a ação humana e a história no centro do processo de conhecimento. Desse ponto de vista, os problemas ambientais são o testemunho vivo de uma racionalidade, cuja expressão econômica encontra seu modelo mais acabado no capitalismo industrial. Tem crescido a consciência de que, mais que efeitos colaterais do desenvolvimento, os enormes riscos ambientais que afetam a vida de inúmeras populações são a essência do modelo de desenvolvimento social e econômico que conhecemos. Assim, os problemas ambientais ameaçam não apenas o futuro físico do planeta, mas, em igual intensidade, questionam o futuro dos valores de nossa sociedade e apontam para a necessidade de uma profunda reorientação nos modos socialmente construídos de conhecer e de se relacionar com a natureza (CARVALHO, 1998, p.17).

Nessa perspectiva, a Educação Ambiental, vista e entendida como prática transformadora da sociedade dispõe de concepções que podem colaborar com a compreensão dos atos e responsabilidades humanos perante o meio ambiente e às presentes gerações. 
A Educação Ambiental crítica objetiva promover ambientes educativos de mobilização desses processos de intervenção sobre a realidade e seus problemas sociambientais, para que possamos netes ambientes superar as armadilhas paradigmáticas e propiciar um processos educativo, em que nesse exercício, estejamos, educandos e educadores, nos formando e contribuindo, pelo exercício de uma cidadania ativa, na transformação da grave crise sociambiental que vivenciamos todos (GUIMARÃES, 2004, p. 30 e 31).

Dessa maneira o processo de Educação Ambiental envolve uma mudança profunda de racionalidade e de olhares perante a natureza, e, portanto "[...] o objeto da Educação Ambiental é de fato, fundamentalmente, nossa relação com o meio ambiente. [...]" (SAUVÉ, 2005, p.317).

Desde que os conceitos de natureza e meio ambiente abandonaram os limites da ciência ecológica e passaram a designar uma agenda de lutas sociais passaram a ser vistos não apenas como mais uma questão a ser equacionada pela lógica científica, mas, sobretudo, como um valor crítico do modo de vida dominante, em torno da qual tem se organizado um importante debate acerca de novos valores éticos, políticos e existenciais que deveriam reorientar a vida individual e coletiva (CARVALHO, 2002, p.85).

Parafraseando Tristão (2004) pode-se afirmar que a Educação Ambiental concentra em sua totalidade dois desafios essenciais a manutenção da vida: a educação e as questões ambientais. Apresenta-se, portanto, como resultado do fracasso de um modelo materialista e reducionista, em que a valoração vigente é apenas a econômica, um modelo que reduz o sujeito a nível material, fragmenta e desvaloriza os saberes culturais.

Contudo, a Educação Ambiental não tem a intenção de impor modelos de comportamentos aos seus participantes, sua intencionalidade reside na construção de um processo transformador e sensibilizador, em que haja uma reflexão sobre os hábitos e atitudes dos cidadãos. Logo, é fácil afirmar que um dos seus maiores desafios é a criação de mecanismos que realmente favoreçam o exercício da cidadania.

Assim, o processo de aprendizagem da Educação Ambiental necessita de estímulos permanentes, onde o indivíduo reconheça e compreenda melhor o ambiente do qual faz parte, e através dos conceitos adquiridos busque novas formas de relacionamento com o meio ambiente, pautadas nos princípios de respeito e integração ambiental.

Paulo Freire, intitulado patrono da educação brasileira, afirma que a educação deve estreitar os laços entre os saberes escolares e os saberes cotidianos, que a formação de sujeitos que possam contribuir para a perpetuação da vida passa obrigatoriamente pelo entendimento do ser coletivo.

revista brasileira educação ambiental 
Essa educação que liberta nega a abstração do homem, seu isolamento e distanciamento do mundo, o que se pretende com essa prática é uma reflexão da relação de pertencimento entre o homem e o mundo (FREIRE, 1996).

Paulo Freire constituiu a sua obra, tendo como base a reflexão sobre a ação educativa transformadora dos homens e do mundo, contra a opressão e a injustiça social, tendo como horizonte a construção de uma nova sociedade. Partindo de experiências concretas, buscando fundamentá-las, constrói um pensamento que une a ação à reflexão, apontando como exigências de uma ação transformadora a constituição de trocas efetivas, recriando o conhecimento e saberes, a partir de temáticas que possibilitem superações das visões e vivências dos sujeitos. Uma vez que as temáticas são significativas, porque percebidas como tal e porque possibilitam a conquista de novas visões de mundo, necessariamente são interdisciplinares, e possibilitam a construção de novas interpretações e ações. Ao considerar todos os participantes da ação educativa como sujeitos, lida com a totalidade do ser humano e sua potencialidade como produto e produtor da História e trata ao mesmo tempo das conquistas cognitivas, afetivas $\mathrm{e}$ das mudanças de valores, procedimentos, perspectivas de mundo (PERNAMBUCO, SILVA, 2006, p.208).

Entende-se, portanto, que a expressão Educação Ambiental contem em si enraizadas dezenas de definições e possibilidade de caminhos e tão vasta quanto às denominações possíveis para a Educação Ambiental é a diversidade de atores, grupos e instituições sociais, que dividem valores, objetivos e interesses comuns. Entretanto, cada um desses componentes dispõe de concepções individuais, que influenciam a forma como a crise ambiental é vista e entendida. Tais concepções também são reflexos das propostas politicopedagógicas por estes defendidas. Por sua vez, essas propostas se movimentam alternadamente entre o meio conservacionista, que pretende manter as relações sociais da forma como estão estabelecidas, e o meio transformador, que propõem mudanças na maneira de compreendê-las (LIMA, 2005).

\section{Do movimento conservacionista à Política Nacional de Educação Ambiental}

Os primeiros movimentos que anunciaram uma preocupação com o meio ambiente começaram a ganhar o mundo a partir da década de 50. A partir desse período uma série de eventos e manifestações colaborou para a disseminação do tema, a iniciar-se pela fundação da UICN - União Internacional para a Conservação da Natureza na Suíça no ano de 1947.

Segundo Guimarães (2007), essas manifestações contribuíram significativamente para o desenvolvimento de uma sensibilização ambiental 
mundial. Em 1968, foi criado o Clube de Roma, que reuniu cerca de trinta representantes de dez países que tinham como pauta a crise ambiental mundial. No ano de 1972 foi realizada a Conferência das Nações Unidas para Defesa do Meio Ambiente Humano, em Estocolmo, na Suécia. Durante esse evento, de importância mundial, foram debatidos temas relevantes relacionados à destruição do meio ambiente, por diversos países.

Entretanto, a maioria dos autores admite como o marco do desenvolvimento da sensibilização ambiental, os anos 60 , que em seus primeiros anos, contou o lançamento do aclamado livro "Primavera Silenciosa", da jornalista americana Rachel Carson. Tal obra desencadeou uma série de discussões sobre a utilização de produtos químicos durante a produção agrícola e sua relação estreita com a diminuição da qualidade de vida (LEITE; MININNI-MEDINA, 2001).

Assim, o surgimento da Educação Ambiental está diretamente ligado à imensa visibilidade e repercussão das ações realizadas pelo movimento ecológico, e foi, de forma gradativa, sendo assimilada como um campo da educação em geral. Neste sentido Tristão (2004) afirma que contrário ao senso comum, o percurso perfeito pela Educação Ambiental é ladrilhado por trajetos irregulares, que foram sendo construídos à medida que palavras como participação, cooperação, solidariedade, diversidade social, biológica e cultural, sociedades sustentáveis e respeito passaram a imprimir sentido na formação de seus fundamentos e ampliação de suas práticas sociais.

No Brasil, a Educação Ambiental começou a ser discutida a partir de debates que ocorreram em meados da década de 1970, reflexos dos grandes eventos ocorridos ao redor do mundo. Em solo nacional as questões que causavam inquietações e pautavam a agenda de discussões dos grupos ambientalistas estavam relacionadas com a poluição atmosférica, principalmente aquela causada pelo polo industrial de Cubatão, no litoral de São Paulo, a instalação, no Rio de Janeiro e em Espírito Santo, de usinas nucleares, além dos problemas alarmantes causados aos ecossistemas pelo uso indiscriminado de agrotóxicos. Contudo, a profundidade dessas discussões era limitada pela forte opressão imposta durante o período militar (TRISTÃO, 2004).

Como referenciado acima, o início da Educação Ambiental coincidiu com um período de grande repressão, o cenário nacional não era um dos mais propícios ao desenvolvimento de uma prática transformadora, crítica e questionadora dos padrões estabelecidos na época, o que acarretou em ações que visavam apenas sensibilizar 0 homem perante a natureza, sem desenvolver ou instigar a reflexão profunda acerca da problemática ambiental e sua inter-relação com as dimensões política e social. 
Uma das consequências do clima autoritário vigente à época sobre esse campo está na constatação de que a EA brasileira, em seus primórdios, foi orientada por uma visão hegemônica de perfil conservacionista, tecnicista, conservadora e apolítica, embora essa não fosse sua expressão exclusiva. Associado a isso, deve-se considerar a forte mediação do Estado brasileiro nesse processo de constituição do debate e da política ambiental brasileira em detrimento da sociedade civil e de uma cultura de participação social (LIMA, 2009, p.149).

Como resultado do momento histórico as questões ambientais durante a década de 60 são abordadas a partir de uma vertente fortemente conservacionista, com ações voltadas para a proteção, conservação, recuperação do meio ambiente e equilíbrio dos ecossistemas. Assim, os problemas ambientais eram tratados de forma pontual e corretiva, não havendo uma preocupação em se questionar o modelo de desenvolvimento econômico que predominava no mundo. Muito antes da Educação Ambiental no Brasil, quer dizer,

[...] muito antes da sua institucionalização no governo federal, temos a existência de um persistente movimento conservacionista até o início dos anos 70, quando ocorre a emergência de um ambientalismo que se une às lutas pelas liberdades democráticas, manifestada através da ação isolada de professores, estudantes e escolas, por meio de pequenas ações de organizações da sociedade civil, de prefeituras municipais e governos estaduais, com atividades educacionais voltadas a ações para recuperação, conservação e melhoria do meio ambiente. Neste período também surgem os primeiros cursos de especialização em Educação Ambiental (BRASIL, 2007, p13).

Mas apesar da existência dessas discussões, ainda que pouco questionadoras, e avanços, a assimilação da problemática ambiental não fazia parte do ideário dos governantes brasileiros. A palavra de ordem na época era desenvolvimento, visto, entendido e praticado como crescimento econômico.

Contrariando as tendências internacionais de proteção ao meio ambiente, o regime militar deu sustentação para o crescimento econômico a qualquer custo, sem nenhuma preocupação ambiental. Isto abrangia alguns mega projetos, como Usina Nucelar de Angra, no Estado do Rio, a Usina Hidrelétrica de Tucuruí, a Transamazônica e o Projeto Carajás, na Amazônia. Em resposta, o Brasil recebeu uma onda de críticas, do Exterior. O governo colocou-se na defensiva, espalhando a opinião de que a defesa do meio ambiente seria uma espécie de conspiração das nações desenvolvidas para impedir o crescimento do país (CZAPSKI, 1998, p. 36). 
Assim, a década de 1970, mundialmente lembrada pela conferência da Organização das Nações Unidas, também tem seu marco em terras brasileiras. No ano seguinte ao que o Brasil, assinou sem restrições a Declaração da ONU sobre o Meio Ambiente, depois de forte pressão mundial, foi criado pelo governo federal o primeiro órgão nacional responsável pelas questões ambientais. A Secretaria Especial do Meio Ambiente tinha como suas principais atribuições o controle da poluição e o desenvolvimento da Educação Ambiental. Ainda na década de 1970 um acontecimento de extrema importância foi a Conferência Internacional de Tbilisi, no ano de 1977. Nesse evento, considerado como o marco da Educação Ambiental, foram apresentadas algumas recomendações às práticas de Educação Ambiental. Apesar da relevância desse evento, o Brasil não participou da Conferência, mas formulou no mesmo período um documento intitulado "Educação Ambiental" que continha os objetivos e princípios da prática brasileira (CZAPSKI, 1998).

A década de 1980 apresenta-se como um importante marco na trajetória da Educação Ambiental nacional, principalmente porque foi nesse período que se entendeu a Educação Ambiental como um processo político, motivado pelos grandes movimentos que insistiam na democratização do poder no Brasil, após anos de um forte regime militar.

As práticas de EA no Brasil surgem principalmente a partir de meados dos anos 80 , neste contexto de difusão da temática ambiental como um valor expresso em um novo marco dos direitos sociais, promovido pelos novos movimentos. Ainda de forma um pouco dispersa, é a partir desta década que educadores passam a se chamar "ambientais" e, num ritmo crescente organizam-se encontros estaduais nacionais, e mais recentemente latino-americanos, que poderiam ser vistos como espaços de construção de uma identidade social e profissional em torno das praticas educativas voltadas para o meio ambiente (CARVALHO, 2002, p.87).

Nesse sentido, além da incorporação das questões ambientais por diversos movimentos sociais, do crescente número de organizações não governamentais voltadas à problemática ambiental e o aumento significativo das produções acadêmicas abordando o assunto, um fato marcante que ocorreu ao final da década de 80 foi a promulgação da Constituição Federal em 1988. Pela primeira vez na história do Brasil, a carta magna trouxe em seu texto um capítulo dedicado ao meio ambiente, reconhecendo-o como um bem de uso comum e indispensável à qualidade de vida, além de enfatizar a obrigação do Estado e de toda a coletividade em garantir um meio ambiente ecologicamente equilibrado para as gerações atuais e futuras. Contudo, é importante ressaltar que a inserção do capítulo sobre meio ambiente na Constituição Federal seguiu uma tendência, sendo precedida por diversos eventos importantes.

revista brasileira educação ambiental 
O processo de institucionalização da Educação Ambiental no governo federal brasileiro teve início em 1973 com a criação da Secretaria Especial do Meio Ambiente (Sema), vinculada à Presidência da República. Outro passo na institucionalização da Educação Ambiental foi dado em 1981, com a Política Nacional de Meio Ambiente (PNMA) que estabeleceu, no âmbito legislativo, a necessidade de inclusão da Educação Ambiental em todos os níveis de ensino, incluindo a educação da comunidade, objetivando capacitá-la para a participação ativa na defesa do meio ambiente. Reforçando essa tendência, a Constituição Federal, em 1988, estabeleceu, no inciso VI do artigo 225, a necessidade de "promover a Educação Ambiental em todos os níveis de ensino e a conscientização pública para a preservação do meio ambiente" (BRASIL, 2007, p.13).

Com a institucionalização da problemática ambiental pelo Estado, através da Constituição Federal, a questão ambiental atinge formalmente o âmbito legal, desse modo a partir de 1988 muitas outras legislações passaram a incorporar as premissas expressas na Constituição Federal. Para a Educação Ambiental, um marco legal de extrema importância foi a aprovação da Política Nacional de Educação Ambiental em 1999, que traz em seu textos os princípios e objetivos da Educação Ambiental nacional, estabelece, ainda, que essa deverá ser uma prática que envolva a sociedade como um todo, em uma permanente busca pela formação de valores, vinculação entre a ética, a educação, o trabalho e as práticas sociais, além do reconhecimento e o respeito à pluralidade e à diversidade individual e cultural (BRASIL, 1999).

\section{A Educação Ambiental crítica: uma adjetivação contrária à Educação Ambiental conservadora}

Compreender o contexto histórico em que a Educação Ambiental começou a desenhar os seus traços no cenário brasileiro é um passo importante para se entender os seus contornos atuais, sua complexidade e diversidade, principalmente porque esse entendimento permite a compreensão de que no Brasil as questões ambientais são praticamente indissociáveis das questões sociais. Neste sentido, é correto afirmar que tanto os movimentos sociais como os ambientais são movimentos que se completam e que são produzidos e agravados "[...] por um mesmo modelo de desenvolvimento capitalista" (LIMA, 2011, p.37).

Assim, tem-se a Educação Ambiental como "fruto de uma demanda para que o ser humano adotasse uma visão de mundo e uma prática social capazes de minimizar os impactos ambientais então prevalecentes" (LAYARGUES, LIMA, 2011, p. 5). Portanto, ao considerar a complexidade e abrangência de áreas que formam a teia denominada de Educação Ambiental, não fica difícil entender a dificuldade em classificá-la ou enquadrá-la em uma única forma. "O mapa das educações ambientais não é auto-evidente, tampouco transparente 
para quem envereda pela multiplicidade das trilhas conceituais, práticas e metodológicas que aí se ramificam" (CARVALHO, 2004, p. 14)

No Brasil, assim como no mundo, a Educação Ambiental não possui apenas uma base única e uniforme, logo "[...] não raras vezes é difícil posicionar-se pelas sendas dos nomes que buscam categorizar, qualificar, adjetivar a Educação Ambiental e aí encontrar um lugar para habitar" (CARVALHO, 2004, p. 14). Há, entretanto, o consenso que os trabalhos de Educação Ambiental podem ser basicamente classificados em duas linhas de estudo: A vertente conservadora ou tradicional e a Educação Ambiental crítica. A diferença básica entre estas duas escolas está justamente em seu "produto" final. Enquanto a Educação Ambiental conservadora tem por objetivo resolver problemas pontuais, a vertente crítica busca uma análise profunda do problema e de seus entornos, levando os seus participantes a refletirem, estabelecendo os níveis de responsabilidade e fornecendo subsídios para mudanças de atitudes de dentro para fora e não de fora para dentro, que não sejam processos mecânicos e sim mudanças de paradigmas.

$\mathrm{Na}$ prática, isso significa que existem muitos caminhos possíveis de conceber e de realizar os meios e os fins da Educação Ambiental. Dependendo desse conjunto complexo de circunstâncias, alguns atores escolhem um determinado caminho, outros escolhem um caminho diferente: uns crêem ser determinante $o$ desenvolvimento da afetividade $e$ sensibilidade na relação com a natureza, outros entendem que é fundamental conhecer os princípios e fundamentos ecológicos que organizam a Vida. Alguns têm forte expectativa no autoconhecimento individual e na capacidade de mudança do próprio comportamento em relação à natureza, outros estão seguros que é preciso articular o problema ambiental com suas dimensões sociais e políticas, entre outras possibilidades (LAYARGUES, LIMA, 2011, p.6).

Guimarães (2004) tece argumentos favoráveis a uma Educação Ambiental que ultrapasse os limites da escola, que seja reflexiva e não individualista e comportamentalista, que seja capaz de mudar o contexto social em que seus atores são inseridos, propondo-se inicialmente a entender a realidade daquele espaço, essas são característica da Educação Ambiental crítica.

Nesta perspectiva a Educação Ambiental crítica, entendida como uma prática reflexiva, proporciona a participação da sociedade na transformação socioambiental, além de ser favorável ao entendimento dos níveis de responsabilidade de cada indivíduo perante o todo. Assim os atores sociais,"[...] por meio da ativação do seu potencial de participação, terão cada vez mais condições de intervir consistentemente e sem tutela nos processos decisórios de interesse público, legitimando e consolidando"(JACOBI, 2005, p. 245). 
Aprender a pensar ao contrário da lógica capitalista, da lógica de mercado e questionar os modelos impostos pela minoria dominante, essas são algumas das transformações possíveis para Loureiro (2004) a partir de uma Educação Ambiental que tenha a capacidade transformadora. Assim, tal prática deve propiciar o exercício da cidadania e o entendimento e compreensão da complexidade das relações existentes no mundo, o desenvolvimento dessa Educação Ambiental deve permitir que os atores envolvidos sejam sujeitos dessa transformação.

Para uma Educação Ambiental crítica, a prática educativa é a formação do sujeito humano enquanto ser individual e social, historicamente situado. Segundo esta orientação, a educação não se reduz a uma intervenção centrada exclusivamente no indivíduo, tomado como unidade atomizada, nem tampouco se dirige apenas a coletivos abstratos. Desta forma, recusa tanto a crença individualista de que mudança social se dá pela soma das mudanças individuais: quando cada um fizer a sua parte. Mas recusa também a contrapartida desta dicotomia que subsume a subjetividade num sistema social genérico $\mathrm{e}$ despersonalizado que deve mudar primeiro para depois dar lugar as transformações no mundo da vida dos grupos e pessoas, aqui vistos como sucedâneos da mudança macro social. Na perspectiva de uma Educação Ambiental crítica, a formação incide sobre as relações indivíduo-sociedade e, neste sentido, indivíduo e coletividade só fazem sentido se pensados em relação. As pessoas se constituem em relação com o mundo em que vivem com os outros e pelo qual são responsáveis juntamente com os outros. $\mathrm{Na}$ Educação Ambiental crítica esta tomada de posição de responsabilidade pelo mundo supõe a responsabilidade consigo próprio, com os outros e com o ambiente, sem dicotomizar e/ou hierarquizar estas dimensões da ação humana (CARVALHO, 2004, p.1920).

Em uma outra ponta, encontra-se a vertente conservadora que tem o seu foco no comportamento humano, na reprodução comportamental considerada correta. "Apoia-se nos princípios da ecologia, na valorização da dimensão afetiva em relação à natureza e na mudança dos comportamentos individuais em relação ao ambiente" (LAYARGUES, LIMA, 2011, p.8), suas ações não provocam transformações, mas sim condicionamentos. Desta forma, o indivíduo não é levado à reflexão, ao questionamento dos atos que causam a problemática ambiental. 
Esta Educação Ambiental tradicional, não pode e/ou não quer perceber as redes de poder que estruturam as relações de dominação presentes na sociedade atual, tanto entre pessoas (relações de gênero, de minorias étnicas e culturais), entre classes sociais, quanto na relação norte-sul entre nações, assim como também entre relações de dominação que se construíram historicamente entre sociedade de natureza. São nessas relações de poder e dominação que podemos encontrar um dos pilares da crise ambiental dos dias de hoje (GUIMARÃES, 2007 p.35).

Guimarães (2004) considera que a vertente conservadora, ao elaborar e praticar seus projetos de Educação Ambiental não considera a vivência, o meio social e os conhecimentos que seus atores já possuem. Essa concepção é pautada, meramente, na reprodução de comportamentos previamente determinados e ditos como ambientalmente corretos, prega a ideia de que as questões ambientais serão resolvidas a partir do desenvolvimento de ações individuais. Outro aspecto relevante apresentado sem seu texto está em seu posicionamento contrário a propostas que privilegiem o campo ambiental ou somente o campo social, nesse aspecto o autor é categórico ao afirmar que é necessário superar essa visão fragmentária, sendo que questões e sociais e ambientais compõem hoje um todo praticamente indivisível.

A Educação Ambiental que denomino conservadora se alicerça nessa visão de mundo que fragmenta a realidade, simplificando e reduzindo-a, perdendo a riqueza e a diversidade da relação. Centrada na parte vela a totalidade em suas complexas relações, como na máquina fotográfica que ao focarmos em uma parte desfocamos a paisagem. Isso produz uma prática pedagógica objetivada no indivíduo (na parte) e na transformação de seu comportamento (educação individualista e comportamentalista). Essa perspectiva foca a realização da ação educativa na terminalidade da ação, compreendendo ser essa terminalidade o conhecimento retido ("educação bancária" de Paulo Freire) e o indivíduo transformado. Espera ainda, pela lógica de que a sociedade é o resultado da soma de seus indivíduos, que se dê à transformação da sociedade. Essa é uma perspectiva simplista e reduzida de perceber uma realidade que é complexa, que vai para além da soma das partes como totalidade. Essa não contempla a perspectiva da educação se realizar no movimento de transformação do indivíduo inserido num processo coletivo de transformação da realidade socioambiental como uma totalidade dialética em sua complexidade. Não compreende que a educação é relação e se dá no processo e não, simplesmente, no sucesso da mudança comportamental de um indivíduo (GUIMARÃES, 2004, p. 26-27). 
É importante destacar que a Educação Ambiental crítica não é uma evolução da Educação Ambiental conservadora, sendo que nunca existiu um momento em que a vertente conservadora evoluiu e se tornou crítica, pelo contrário a Educação Ambiental crítica nasce em resposta, em oposição às concepções da Educação Ambiental dita conservadora (GUIMARAES, 2004).

Por fim, fica claro que o eixo da Educação Ambiental que se pretende aplicar relaciona-se diretamente com os objetivos e intencionalidades do projeto a ser desenvolvido. Desta forma, a escolha entre práticas que privilegiem uma reflexão crítica sobre a realidade ou apenas condicionem os seus participantes a chegarem ao resultado esperado pode revelar também a visão dos seus idealizadores, seu modo de ver, perceber e entender a crise ambiental e sua relação com cada indivíduo e com o todo.

\section{Conclusões}

A Educação Ambiental deve ser um processo que permita, a partir de uma sensibilização individual, a existência de uma ação coletiva. Contudo, para que isso ocorra, todo esse processo deve considerar e incorporar as questões culturais, históricas, políticas e sociais dos indivíduos que formam o mosaico da Educação Ambiental. Assim, suas propostas devem privilegiar as ações que visem uma transformação do sujeito, essa prática deverá ser emancipatória, permitindo que seus atores desvendem a crise ambiental e vejam além da lógica comportamentalista, construindo assim uma visão crítica da relação entre o homem e o meio ambiente, bem como a compreensão da necessidade de se desconstruir os ideários e práticas que alimentam a máquina dominadora da sociedade.

Contudo, essa sensibilização que leva a reflexão, que desvenda os olhares turvos de indivíduos, muitas vezes ensinados a enxergarem de forma cartesiana, não compreende um processo simples e linear. Essa sensibilização intercala os meios culturais, ambientais, sociais e políticos, devendo promover ações que tornem cada indivíduo sujeito de sua realidade, com capacidade para pensar e agir na contramão.

Assim, apesar da beleza e liberdade expressas nos princípios de uma Educação Ambiental crítica, que pretende transformar, emancipar e formar um sujeito atuante e questionador dos moldes viventes atuais, ainda hoje, a prática é reduzida, apenas, à reprodução de comportamentos. Reprodução está, tantas vezes, apresentadas de forma "[...] descontextualizadas da realidade socioambiental' (GUIMARAES, 2004, p.31), herança de uma Educação Ambiental conservadora e comportamentalista. 


\section{Referências}

BRASIL. Lei $n^{\circ}$ 9.795, de 27 de abril de 1999. Dispõe sobre a Educação Ambiental, institui a Política Nacional de Educação Ambiental e dá outras providências. DF, 1999. 1p. Disponível em: <http://www.planalto.gov.br>. Acesso em: 12 jan. 2015.

BRASIL. Secretaria de Educação Continuada, Alfabetização e Diversidade. Educação Ambiental: Aprendizes de sustentabilidade. Brasília, 2007, 109 p.

CARVALHO, I.C.M. Mudando as Lentes: Repensando as relações entre sociedade, natureza e cultura. In: Em direção ao mundo da vida: Interdisciplinaridade e Educação Ambiental. Brasília: Ministério do Meio Ambiente, Diretoria de Educação Ambiental, 1998. p. 18-23.

CARVALHO, I.C.M. O 'ambiental' como valor substantivo: uma reflexão sobre a identidade da Educação Ambiental. In: Sauvé, L. ORELLANA, I. SATO, M. Textos escolhidos em Educação Ambiental: de uma América à outra. Montreal, Publications ERE-UQAM, 2002, Tomo I, 9. 85-90 (versão em português).

CARVALHO, I.C.M. Educação Ambiental crítica: nomes e endereçamentos da educação. In: LAYRARGUES, P.P. (Coord.). Identidades da Educação Ambiental brasileira. Brasília: Ministério do Meio Ambiente, Diretoria de Educação Ambiental, 2004. p. 13-24.

CZAPSKI, S. A implantação da Educação Ambiental no Brasil. Brasília: Ministério da Educação e do Desporto,1998. 166p.

FREIRE, P. Pedagogia da Autonomia: saberes necessários à prática educativa. São Paulo: Paz e Terra, 1996.

GUIMARÃES, M. A formação de educadores ambientais. Campinas: Papirus (Coleção Papirus Educação), 2007.

GUIMARÃES, M. Educação Ambiental crítica. In: LAYRARGUES, P.P. (Coord.). Identidades da Educação Ambiental brasileira. Brasília: Ministério do Meio Ambiente, Diretoria de Educação Ambiental, 2004. p. 25- 34.

JACOBI. P.R. Educação Ambiental: o desafio da construção de um pensamento crítico, complexo e reflexivo. Educação e Pesquisa, São Paulo, v.31, n.2, p. 233-250, mai./ago.2005.

LAYRARGUES, P.P, LIMA, G.L.C. Mapeando as macro-tendências políticopedagógicas da Educação Ambiental contemporânea no Brasil. Anais do VI Encontro "Pesquisa em Educação Ambiental" A Pesquisa em Educação Ambiental e a Pós-Graduação no Brasil. Ribeirão Preto, 2011.

LEFF, E. Saber Ambiental: sustentabilidade, racionalidade, complexidade, poder. Tradução de Lúcia Matilde Edilch Orth. Petrópolis, RJ: Vozes, 2001. 
LEITE, A.L.T.A.; MININNI-MEDINA, N. Educação Ambiental: curso básico à distância: Educação e a Educação Ambiental. 2 ed. 5 v. Brasília: MMA, 2001.

LIMA, G.L.C. Formação e dinâmica do campo da Educação Ambiental no Brasil: emergência, identidades, desafios. 2005. 207p. Tese (Doutorado em Ciências Sociais), Universidade Estadual de Campinas, Campinas, 2005.

LIMA, G.L.C. Educação Ambiental crítica: do socioambientalismo às sociedades sustentáveis Educação. Educação e Pesquisa, São Paulo, v.35, n.1, p. 145-163, jan./abr.2009.

LIMA, G.L.C. Educação Ambiental no Brasil: Formação, identidades e desafios. 1.ed. Campinas: Papirus, 2011.

LOUREIRO, C.F.B. Educação Ambiental Transformadora. In: LAYRARGUES, P.P. (coord). Identidades da Educação Ambiental brasileira. Ministério do Meio Ambiente. Diretoria de Educação Ambiental; Ministério do Meio Ambiente, 2004. p. 65-82.

PERNANBUCO, M.M; SILVA, A.F.G. Paulo Freire: a educação e a transformação do mundo. In: CARVALHO, I.C.M; GRÜN, M; TRAJBER, R. Pensar o Ambiente: bases filosóficas para a Educação Ambiental. Ministério da Educação, Secretaria de Educação Continuada, Alfabetização e Diversidade, UNESCO, 2006. p. 207- 220.

SAUVÉ, L. Educação Ambiental: Possibilidades e Limitações. São Paulo, v. 31 , n. 2, p. 317-322, maio/ago. 2005. Disponível em: <http://www.scielo.br/pdf/\%0D/ep/v31n2/a12v31n2.pdf>. Acesso em: 12 jan. 2015.

TRISTÃO, M. Educação Ambiental na formação de professores: redes de saberes. 1 ed. São Paulo: Annablume, 2004. 236p. 